Research Article

\title{
Analysis of Machining Parameters in WEDM of Al/SiCp20 MMC Using Taguchi-Based Grey-Fuzzy Approach
}

\author{
Mangesh R. Phate $\mathbb{D}^{1},{ }^{1}$ Shraddha B. Toney, ${ }^{2}$ and Vikas R. Phate ${ }^{3}$ \\ ${ }^{1}$ Department of Mechanical Engineering, All India Shri Shivaji Memorial Society's College of Engineering, \\ Shivajinagar, Pune 411001, Maharashtra, India \\ ${ }^{2}$ Department of Computer Engineering, Sinhgad Institute of Technology and Science, Narhe, Pune 411041, \\ Maharashtra, India \\ ${ }^{3}$ Department of Electronics, Government Polytechnic, Murtizapur, Akola 444107, Maharashtra, India
}

Correspondence should be addressed to Mangesh R. Phate; mangeshphate03@gmail.com

Received 22 August 2018; Revised 10 December 2018; Accepted 19 December 2018; Published 25 February 2019

Academic Editor: Ricardo Perera

Copyright (c) 2019 Mangesh R. Phate et al. This is an open access article distributed under the Creative Commons Attribution License, which permits unrestricted use, distribution, and reproduction in any medium, provided the original work is properly cited.

\begin{abstract}
Aluminium silicate metal matrix composite (AlSiC MMC) is satisfying the requirement of material with good mechanical, thermal properties, and good wear resistance. But the difficulties during the machining are the main hurdles to its replacement for other materials. Wire electric discharge machining (WEDM) is a very effective process used for this type of difficult-to-cut material. So an effort has been taken to find out the most favourable level of input parameters for WEDM of AlSiC (20\%) composite using a Taguchi-based hybrid grey-fuzzy grade (GFG) approach. The plan for experimentation is designed using Taguchi's $\mathrm{L}_{9}\left(2^{3}\right)$ array. The various process parameters considered for the investigation are pulse on time $\left(T_{\mathrm{ON}}\right)$, pulse off time $\left(T_{\mathrm{OFF}}\right)$, wire feed rate (WFR), and peak current (IP). Surface integrity such as surface roughness measured during the different types of cutting (along straight, inclined, and curvature directions) is considered in the present work. Grey relational analysis (GRA) pooled with the fuzzy logic is effectively used to find out the grey-fuzzy reasoning grade (GFRG). The Taguchi approach is coupled with the GFRG to obtain the optimum set of process parameters. From the experimental findings, it has been observed that the most economical process parameters for WEDM of AlSiCp20 were the pulse on time is 108 microsec, pulse off time is 56 microsec, wire feed rate (WFR) is $4 \mathrm{~m} / \mathrm{min}$, and peak current (IP) is $11 \mathrm{amp}$. From the analysis of variance (ANOVA), it is observed that the pulse on time is the foremost influencing parameters that contribute towards GFRG by $52.61 \%$, followed by the wire feed rate (WFR) $38.32 \%$ and the current by $5.45 \%$.
\end{abstract}

\section{Introduction}

There is a chain of significant changes in the industrial needs that are characterized by complexity and volatility. Today, an industry needs a material which has properties such as durability, high strength, low weight, and low density which encourage the worldwide researcher to focus on the field of material and their applications. This switched the researcher towards the development of metal matrix composite. In the recent couple of years, the aluminium base composite fits the industrial requirements and use for numerous engineering applications such as piston, cylinder components of the automobiles, and aerospace applications. Depending upon the work piece geometry, any machining operation can have more than one type of metal cutting operation that it normally uses. The three most common and easy types of metal cutting operations are straight machining, angular machining, and curvature machining or cutting. A straight cut is a machining operation which is used in almost all the machining operations. This type would allow the tool to move in the straight direction as shown in Figure 1(a). In the angular machining, the tool moves in the inclined direction for getting the triangular or trapezoidal shape. This type would allow the tool to move in the inclined or angular direction as shown in Figure 1(b). The last and the most important type of machining is the machining along the 
curvature direction as shown in Figure 1(c). In this type, the tool moves in the curvature direction to get the circular or curvature shape. The accurate and precise metal removal process such as wire electrical discharge machining (WEDM) utilizes a tough wire to take away redundant material from the fixed raw plate to get the required size and shape.

Phate et al. [1,2] used an approach of dimensional analysis to correlate the various machining parameters in dry machining of ferrous and nonferrous material. Ilhan and Mehmet [3] used multiple regressions and the artificial neural network for the turning process. They analyzed the impact of cutting parameters such as feed, cutting speed, and depth of cut on surface quality. Gaitinde et al. [4] used ANN, i.e., artificial neural network, technique for the analyzed the performance of conventional wiper and ceramic inserts in machining. An acceptable and efficient result was obtained by these techniques. Jamadar and Vakharia [5] used DA approach and ANN based on feed-forward backpropagation training network to analyze the responses due to bearing component defects to quantify the level of damage of the components. Acceptable results were obtained by the DA method. Bobbili et al. [6] evaluated the significance machine variables such as pulse on time, flushing pressure, input power, thermal diffusivity, and latent heat of vaporization on responses. Buckingham's $\pi$ theorem is used for the model formulation of the materials such as aluminium alloy 7017 and rolled homogeneous armour. Kolli and Kumar [7] used the Taguchi method to analyze the impact of coolant on the discharge of WEDM of titanium alloy. They analyzed the output parameters such as recast layer thickness (RLT), material removal rate, surface roughness, and tool wear rate (TWR). Saha and Mondal [8] investigated the WEDM process of nanostructured hardfacing material using response surface methodology coupled with the principal component analysis. Mevada [9] investigated two responses, i.e., material removal rate and surface roughness. This analysis was executed to find out the optimum level of parameters for higher material removal rate at lower surface roughness for Inconel 600 material. The experiments have been conducted by changing pulse on time, pulse off time, and peak current. Huang et al. [10] observed the influence of various process parameters on surface quality, material removal rate, and average gap voltage in the WEDM of high hardness tool steel YG15. Regression models are used to obtain the optimum cutting parameter combination. Pulse on time, cutting feed rate, and water pressure were more significant than other factors on MRR. Tzeng et al. [11] proposed a valuable process parameter optimization approach which integrates various approaches such as response surface methodology (RSM), Taguchi's method, a back-propagation neural network $(\mathrm{BPNN})$, and a genetic algorithm (GA) on engineering optimization concepts to determine parameter settings of the WEDM process under consideration of multiple responses. Material removal rate and work piece surface finish on process parameters during the manufacture of pure tungsten profiles. Phate et al. [12-14] used the approach based on the dimensional analysis for the turning of materials such as Al 6063, brass, Steel EN1A, EN8, and SS 304 used for the experimentation. The surface roughness model is formulated for the various materials using DA approach. A random plan of experimentation is used for the data collection. A good agreement with experimental and calculated surface roughness has observed in the presented work. Kadu et al. [15] used dimensional analysis approach for analyzing the performance of boring machining operation. The factors such as depth of cut, cutting speed, insert material, and machining environment along with the diameter and length of the tool have been considered as the influencing parameters. The principle of max-min has been used for optimizing the performance parameters such as surface roughness and the cutting time. Rao et al. [16] used parametric analysis of WEDM on residual stresses developing in the machining of $\mathrm{Al}$ alloy. The well-known Taguchi method $[17,18]$ has been used for the analysis and experimental findings. The signal-noise analysis was conducted, and the best level of ratio, pulse on time, input power, and the servo voltage were obtained through it. Kumar and Batra [19] used the EDM process for the surface modification using tungsten powder-mixed dielectric fluid. OHNS die steel has used for the experimentation.

\section{Materials and Methods}

2.1. Manufacturing of Al/SiCp20 MMC. Aluminium 2124 is an aluminium alloy with copper as the primary alloying elements. It has high strength and weight ratio. The basic properties of base metal Al 2121 alloy are outlined in the following Table 1.

The filler material used for the MMC preparation consists of silicon carbide ( $\mathrm{SiC}$ ). It has a better thermal conductivity, high melting point, low thermal expansion, high strength, and the high hardness value. The metal matrix composite AlSiC is used for various industrial applications. The Sic powder is as shown in Figure 2(a). The powder of $\mathrm{Al} 2124$ alloy is kept in the crucible and is preheated in the furnace to a temperature of $1000^{\circ} \mathrm{C}$ as shown in Figure 2(b). The wood pattern of required size is prepared as shown in Figure 2(c). The next step is the sand mould preparation and the cope and drag preparation as shown in Figures 2(d) and 2(e). After the mould preparation, the heated liquid metal is poured in the mould and allows cooling slowly. The reinforced Sic particles are added into the molten metal as shown in Figures 2(e)-2(g). After the removal of the cope and drag, the composite specimen of required size and shape is removed from the casting.

2.2. Experimental Details. The fabricated rectangular specimens are subjected to machining through the WEDM. The electrode used for the machining operation is the $0.25 \mathrm{~mm}$ diameter brass wire. The details are shown in Table 2.

The number of experiments run on Ultracut S0 wire Electronic Discharge Machine (Electronics Make Elektra, Pune) is as shown in Figure 3. The work piece material is $\mathrm{Al} /$ $\mathrm{SiC}$ with $20 \%$ concentration of silicate MMC with the dimensions of $80 \mathrm{~mm} \times 55 \mathrm{~mm} \times 20 \mathrm{~mm}$ was used for 


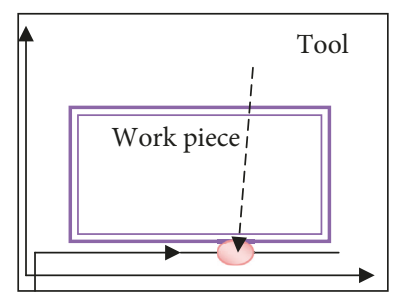

(a)

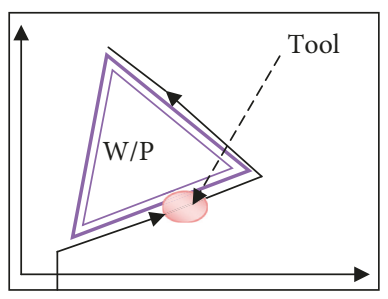

(b)

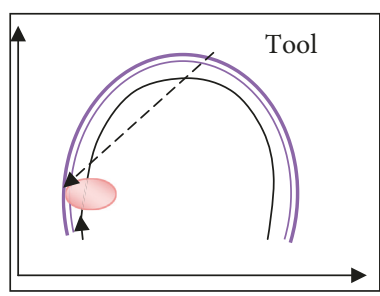

(c)

Figure 1: Different types of cut involved in the geometry. (a) Straight cut. (b) Angular cut. (c) Curvature cut.

Table 1: Properties of base metal Al 2124.

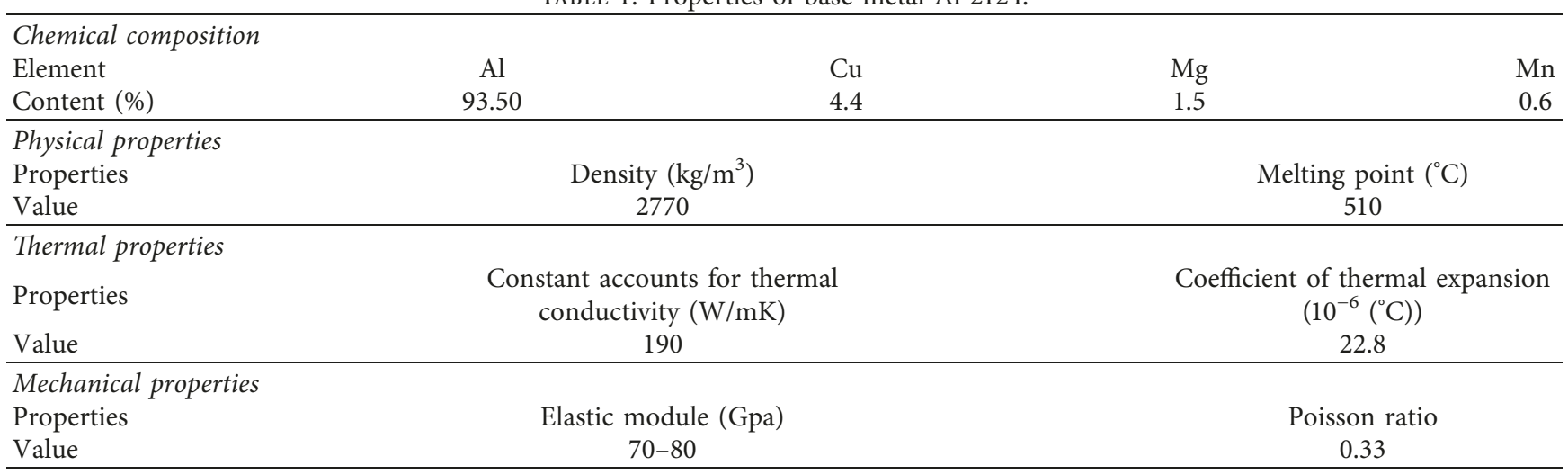

experimentation. The edges of each work piece were trimmed to make accurate positioning on the machine table. Reference or setting point on the specimen was located for reference setting of work piece. Based on the imported CAD drawing of the work piece, the profile has been created and used for the actual cutting. In order to calculate the surface quality of specimens, a Mitutoyo surface profile meter with $2.5 \mathrm{~mm}$ sampling length and cutoff of $0.25 \mathrm{~mm}$ was used. For obtaining the error-free value of the surface roughness, three replicates have been used to minimize the effect of the manmade error. The size and shape of the final work piece is shown in Figures 4-6.

Table 3 shows the various levels of the process parameters used for the experimentation. The results are shown in Table 4.

\section{Grey Relational Analysis}

The grey relational analysis (GRA) is the multiresponse optimization approach applied to find out the best set of input parameters for determining the optimum conditions of various input parameters. The following steps are involved in the GRA approach (shown in Figure 7).

3.1. Normalization of the Raw Data. In GRA, the real or experimental response cannot be used for further analysis, but the data are normalized before the subsequent analysis. In the normalizing phase, the original data sequence is transformed between the numbers 0.00 and 1.00. For response which is maximized, the "Higher-the better" approach of optimization is used. In the present work, for the "Higher-the better" condition, the original responses are normalized by using the following equation:

$$
X_{i}^{*}(j)=\frac{X_{i}^{k}(j)-\min X_{i}^{k}(j)}{\max X_{i}^{k}(j)-\min X_{i}^{k}(j)},
$$

where $X_{i}^{k}(j)$ is the original sequence, $X_{i}^{*}(j)$ is the sequence after data preprocessing, $\min X_{i}^{k}(j)$ is the minimum value of $X_{i}^{k}(j)$, and $\max X_{i}^{k}(j)$ is the maximum value of $X_{i}^{k}(j)$.

3.2. Calculate Coefficient of Grey Relational Analysis (GRA). The next step after the data normalization is to find out the grey relational coefficient. To find out the deviation sequence, first find out the maximum value of the normalized data sequence. Let " $M$ " be the maximum value which is known as the reference value. The maximum value " $M$ " is given by the following equation:

$$
M=\max \left(X_{i j k}\right) \text {. }
$$

3.3. Calculation for Deviational Sequence $\left(\partial_{i j k}\right)$. The deviation is the difference between normalized sequence value and the reference value $(M)$. This is given by the following equation:

$$
\partial_{i j k}=X_{i j k}-M .
$$




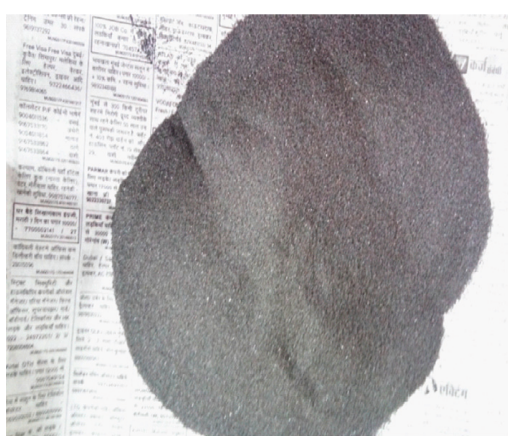

(a)

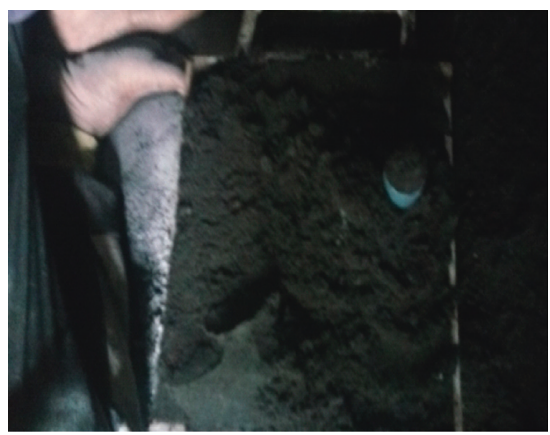

(d)

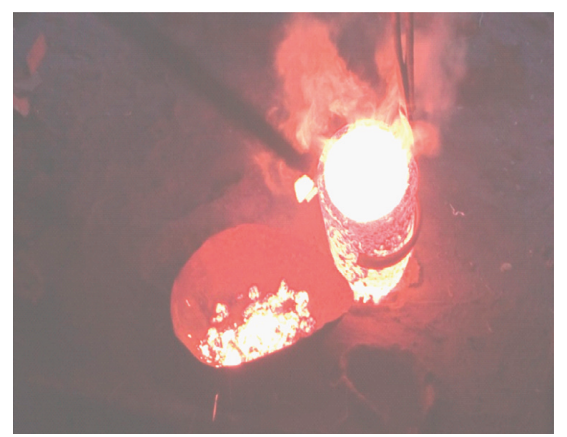

(b)

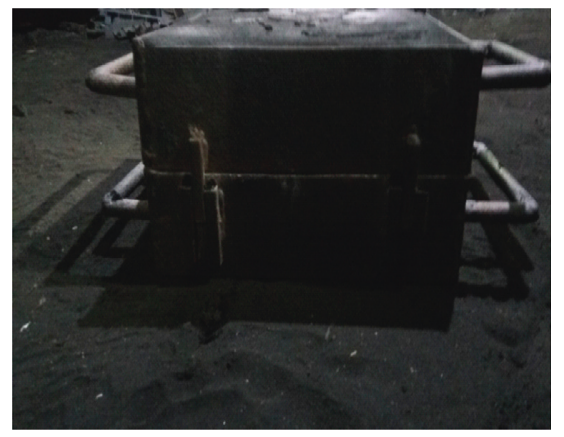

(e)

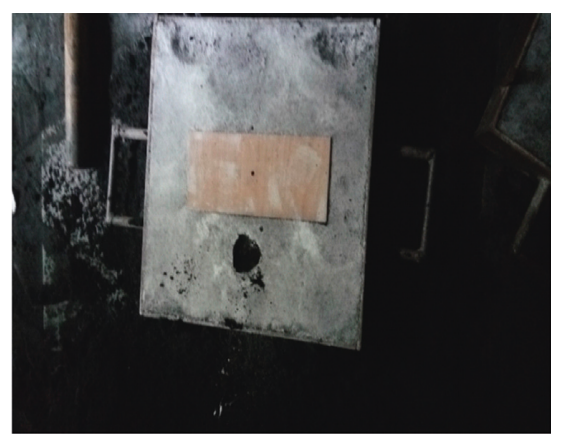

(g)

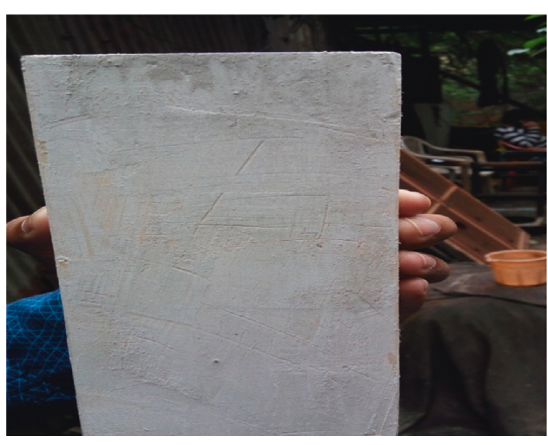

(c)

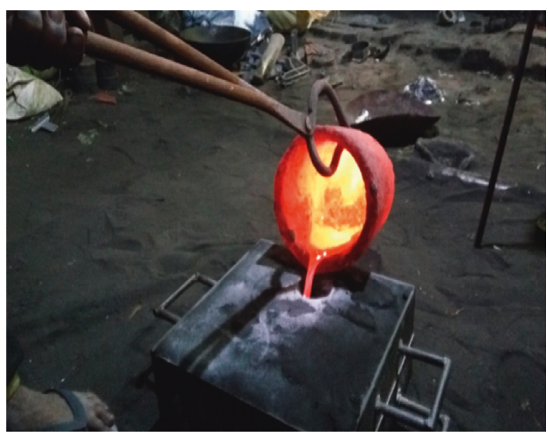

(f)

Figure 2: Steps in the composite preparation. (a) Sic powder. (b) Melting of metal. (c) Pattern making. (d) Sand mould preparation. (e) Cope and Drag preparation. (f) Poring metal. (g) Solidification.

TABLE 2: Experimental setup details.

\begin{tabular}{lcc}
\hline S. No. & Experimental facility & Specifications \\
\hline 1 & Wire electric discharge & $\begin{array}{c}\text { Ultracut S0 wire Electronic } \\
\text { Discharge Machine (M/S } \\
\text { Electronica, Ultracut So } \\
\text { Model, Pune, Maharashtra, } \\
\text { India) }\end{array}$ \\
2 & Electrode/wire & Brass cutting wire (diameter \\
3 & Type of dielectric fluid & of 0.25 mm) \\
4 & Water pressure & 15 lit/min \\
5 & Wire tension & Setting 9 (1150 to 1200 grams) \\
6 & Servo voltage & 30 volts \\
7 & Device used for measuring & Make: Mitutoyo, model: \\
& surface roughness. & Surftest SJ-201 \\
\hline
\end{tabular}

3.4. Calculation for Grey Relational Coefficient. The grey relational coefficient is given by the following equation:

$$
\varepsilon_{i}(k)=\frac{\partial_{\min }+\alpha \partial_{\max }}{\partial_{o i}(k)+\alpha \partial_{\max }},
$$

where $\partial_{o i}(k)$ is the deviation sequence of reference sequence which is given by the following equation:

$$
\begin{aligned}
\partial_{o i}(k) & =\left\|X_{o}^{*}(k)-X_{i}^{* O}(k)\right\|, \\
\partial_{\max } & =\max \max \left\|X_{o}^{*}(k)-X_{j}^{* O}(k)\right\|, \\
\partial_{\max } & =\min \min \left\|X_{o}^{*}(k)-X_{j}^{* O}(k)\right\|,
\end{aligned}
$$

where " $\alpha$ " is the distinguishing coefficient. Generally, 0.5 is being used, i.e., $\alpha \in[0,1]$. The grey relational grade is 


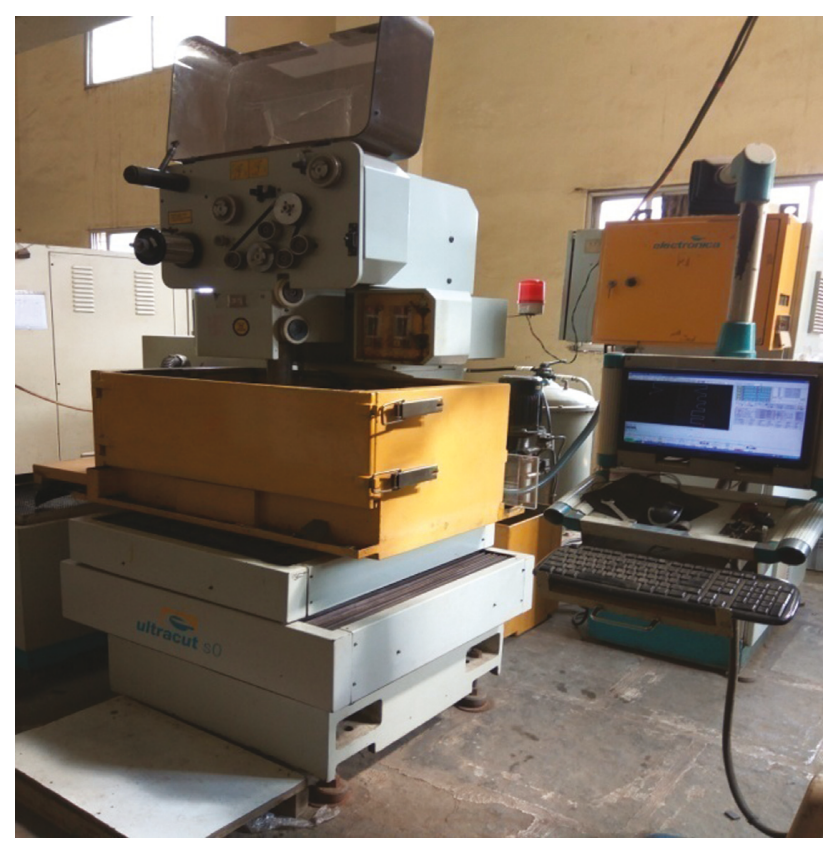

Figure 3: WEDM tool used for experimentation.

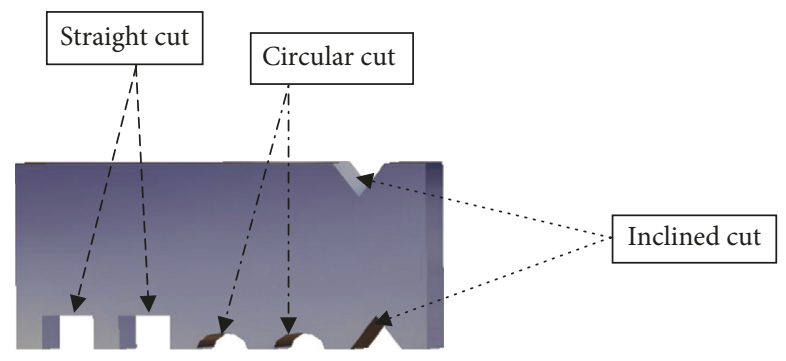

FIGURE 4: Work piece 3D geometry.
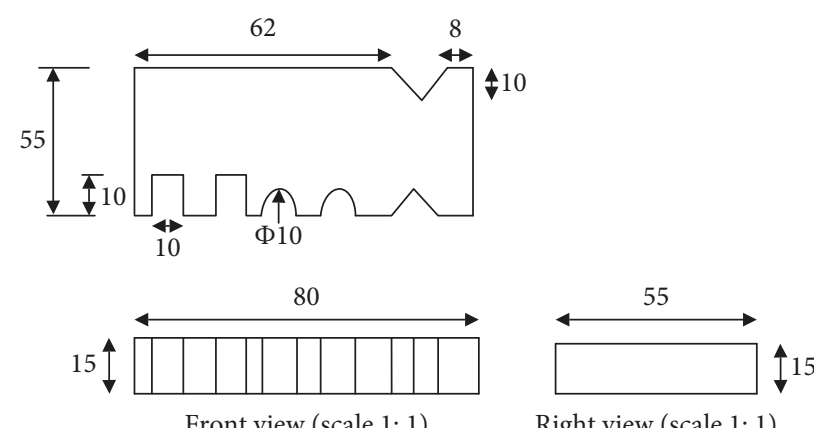

FIgURE 5: Work piece 2D geometry.

calculated by taking the mean of the grey relational coefficient of all responses. The grey relational grade is given by the following equation:

$$
r_{i}=\frac{1}{n} \sum_{k=1}^{n} i \partial_{i}(k)
$$

3.5. Calculation of Grey-Fuzzy Reasoning Grade. The fuzzy inference system consists of four submodels which are shown in Figure 7. The membership function is selected on the basis of database available. The fuzzification interface is used for converting the available input data into matched linguistic numbers. The defuzzification units are used to 


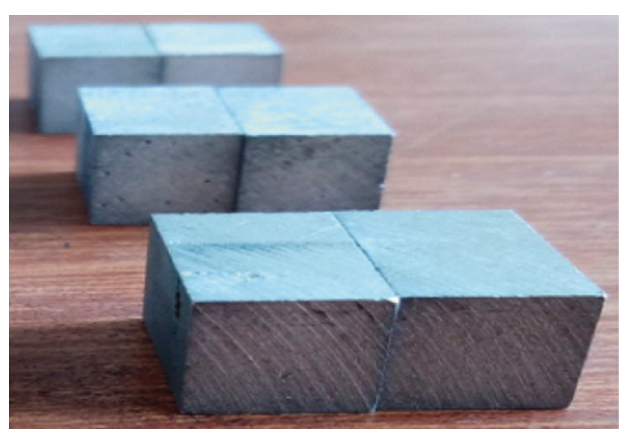

(a)

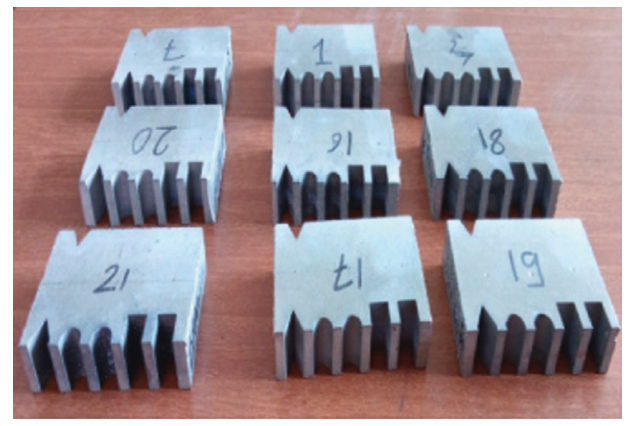

(c)

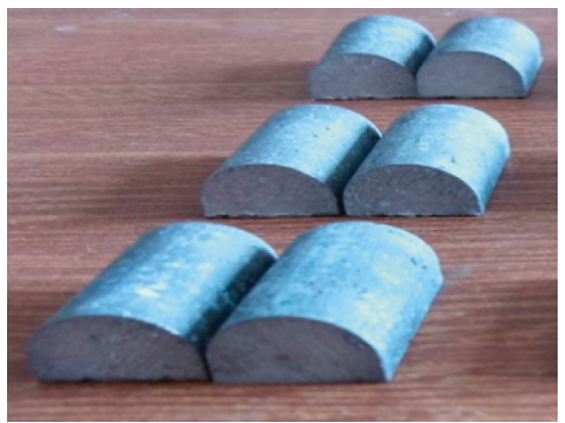

(b)

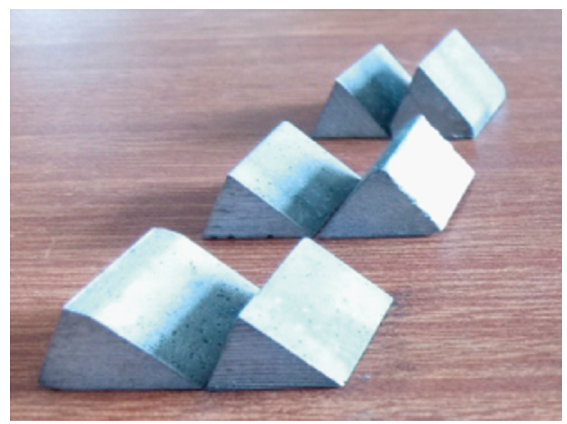

(d)

FIGURE 6: Al/Sic work piece components during different cutting.

TABLE 3: Input levels of the various input process parameters.

\begin{tabular}{lcccc}
\hline Parameters & Notation & First level & Second level & Third level \\
\hline Pulse on (microsec) & $T_{\text {ON }}$ & 108 & 110 & 112 \\
Pulse off (microsec) & $T_{\text {OFF }}$ & 56 & 54 & 52 \\
Wire feed rate $(\mathrm{m} / \mathrm{min})$ & WFR & 4 & 5 & 6 \\
Current (IP) $(\mathrm{amp})$ & IP & 11 & 12 & 13 \\
\hline
\end{tabular}

TABle 4: Taguchi's $\mathrm{L}_{9}$ orthogonal array (OA'S) for experimentation and experimental results.

\begin{tabular}{lccccccccccc}
\hline S. No. & $T_{\text {ON }}$ & $T_{\text {OFF }}$ & WFR & IP & $T_{\text {ON }}$ & $T_{\text {OFF }}$ & WFR & IP & RaS & RaC & RaI \\
\hline 1 & 1 & 1 & 1 & 1 & 108 & 56 & 4 & 11 & 2.549 & 2.469 & 2.605 \\
2 & 1 & 2 & 2 & 2 & 108 & 54 & 5 & 12 & 3.069 & 3.135 & 4.295 \\
3 & 1 & 3 & 3 & 3 & 108 & 52 & 6 & 13 & 2.935 & 2.379 & 2.792 \\
4 & 2 & 1 & 2 & 3 & 110 & 56 & 5 & 13 & 2.932 & 3.315 & 3.065 \\
5 & 2 & 2 & 3 & 1 & 110 & 54 & 6 & 11 & 2.789 & 2.695 & 2.265 \\
6 & 2 & 3 & 1 & 2 & 110 & 52 & 4 & 12 & 3.019 & 2.802 & 2.759 \\
7 & 3 & 1 & 3 & 2 & 112 & 56 & 6 & 12 & 3.052 & 3.762 & 3.119 \\
8 & 3 & 2 & 1 & 3 & 112 & 54 & 4 & 13 & 3.599 & 2.999 & 3.815 \\
9 & 3 & 3 & 2 & 1 & 112 & 52 & 5 & 11 & 3.352 & 3.012 & 3.072 \\
\hline
\end{tabular}

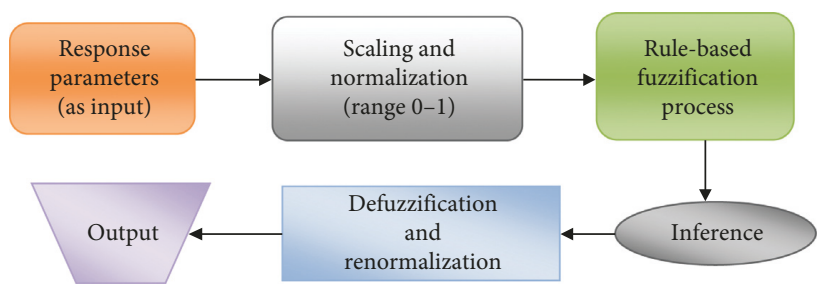

Figure 7: Elements of fuzzy interface system. 
convert the results from fuzzy to crisp responses. If-then control rule with three inputs, i.e., the experimental responses and one output (grey-fuzzy reasoning grade), is used in the rule-based fuzzification process as follows:

(i) Rule 1: if $\mathrm{Y}_{1}$ is $\mathrm{A}_{1}, \mathrm{Y}_{2}$ is $\mathrm{B}_{1}$, and $\mathrm{Y}_{3}$ is $\mathrm{C}_{1}$, then $\mathrm{Z}$ is $\mathrm{D}_{1}$ else

(ii) Rule 2: if $\mathrm{Y}_{1}$ is $\mathrm{A}_{2}, \mathrm{Y}_{2}$ is $\mathrm{B}_{2}$, and $\mathrm{Y}_{3}$ is $\mathrm{C}_{2}$, then $\mathrm{Z}$ is $\mathrm{D}_{2}$ else

(iii) Rule $N$ : if $\mathrm{Y}_{1}$ is $\mathrm{A}_{n}, \mathrm{Y}_{2}$ is $\mathrm{B}_{n}$, and $Y_{3}$ is $\mathrm{C}_{n}$, then $\mathrm{Z}$ is $\mathrm{D}_{n}$ else

where $\mathrm{A}_{j}, \mathrm{~B}_{j}$, and $C_{j}$ are fuzzy subsets which are defined by the related membership functions.

\section{Results and Discussion}

ANOVA used to find out the contribution of each input parameter over the responses chosen. Findings from the ANOVA table can be used to recognize the variables accountable for the analysis. Taguchi's $\mathrm{L}_{9} \mathrm{OA}^{\prime}$ 's are used to conduct the experiments in WEDM. In this study, totally nine AlSiC20\% composite work pieces are used for the investigation. Using the surface roughness tester (Mitutoyo, Model, Surftest SJ-201), the output responses, i.e., surface roughness during the different types of machining, are measured which are given in Table 4 .

From the interpretation made from the experimental data related to the responses, i.e., surface roughness for all three types of cutting (straight, curvature, and inclined) as shown in Table 4, it has been observed that, when pulse on time $\left(T_{\mathrm{ON}}\right)$ is increased from 108 to 110 microsec, surface roughness increases by $2.17 \%$ during the straight cutting, by $10.37 \%$ during curvature cutting, and reduces by $16.56 \%$ during inclined cutting. An increase in surface roughness by $14.45 \%, 10.93 \%$, and $23.70 \%$ is noticed during the straight, curvature, and inclined cutting, respectively, when the pulse on time $\left(T_{\mathrm{ON}}\right)$ is further increased from 110 to 112 microsec.

An increase in surface roughness by $10.83 \%$ and $18.02 \%$ and reduction by $7.51 \%$ are observed during straight, inclined, and curvature cutting, respectively, when the pulse off time $\left(P_{\mathrm{OFF}}\right)$ is changed from 56 to 54 microsec. A reduction in surface roughness by $1.58 \%, 7.20 \%$, and $16.88 \%$ is noticed during the straight, curvature, and the inclined cutting when the pulse off time $\left(P_{\mathrm{OFF}}\right)$ is changed from 54 to 542 microsec.

An increase in surface roughness by $2.02 \%, 14.40 \%$, and $13.62 \%$ is noticed during the straight, curvature, and inclined cutting, respectively, when the wire feed rate (WFR) is increased from 4 to $5 \mathrm{~m} / \mathrm{min}$. A decrease in surface roughness by $6.18 \%, 6.62 \%$, and $21.62 \%$ is noticed during the straight, curvature, and the inclined cutting, when the wire feed rate (WFR) is further increased from 5 to $6 \mathrm{~m} /$ $\min$.

Similarly an increase in surface roughness by $5.17 \%$, $18.64 \%$, and $28.10 \%$ is observed during straight, curvature, and inclined cutting, respectively, when the input current is
TABLE 5: Normalization and the deviation values during the GRA.

\begin{tabular}{lcccccc}
\hline \multirow{2}{*}{ Trial no } & \multicolumn{3}{c}{ Normalized value } & \multicolumn{3}{c}{ Deviation value } \\
& $\mathrm{RaS}$ & $\mathrm{RaC}$ & $\mathrm{RaI}$ & $\mathrm{RaS}$ & $\mathrm{RaC}$ & $\mathrm{RaI}$ \\
\hline 1 & 1.000 & 0.935 & 0.8325 & 0.000 & 0.065 & 0.1675 \\
2 & 0.5048 & 0.453 & 0.000 & 0.495 & 0.547 & 1.000 \\
3 & 0.6324 & 1.000 & 0.7404 & 0.368 & 0.000 & 0.2596 \\
4 & 0.6352 & 0.323 & 0.6059 & 0.365 & 0.677 & 0.3941 \\
5 & 0.7714 & 0.772 & 1.000 & 0.229 & 0.228 & 0.000 \\
6 & 0.5524 & 0.694 & 0.7567 & 0.448 & 0.306 & 0.2433 \\
7 & 0.521 & 0.000 & 0.5793 & 0.479 & 1.000 & 0.4207 \\
8 & 0.000 & 0.552 & 0.2365 & 1.000 & 0.448 & 0.7635 \\
9 & 0.2352 & 0.542 & 0.6025 & 0.765 & 0.458 & 0.3975 \\
\hline
\end{tabular}

TABLE 6: Calculated grey relational coefficient, grade, and rank for each experiment.

\begin{tabular}{lccccc}
\hline Trial no & $\mathrm{RaS}$ & $\mathrm{RaC}$ & $\mathrm{RaI}$ & Grey rational grade & Rank \\
\hline 1 & 1.000 & 0.885 & 0.74908 & 0.87797 & 1 \\
2 & 0.502 & 0.478 & 0.33333 & 0.43782 & 8 \\
3 & 0.576 & 1.000 & 0.65824 & 0.74484 & 3 \\
4 & 0.578 & 0.425 & 0.55923 & 0.52077 & 5 \\
5 & 0.686 & 0.686 & 1.000 & 0.79088 & 2 \\
6 & 0.528 & 0.62 & 0.67263 & 0.60691 & 4 \\
7 & 0.511 & 0.333 & 0.54307 & 0.46237 & 7 \\
8 & 0.333 & 0.527 & 0.39571 & 0.41877 & 9 \\
9 & 0.395 & 0.522 & 0.55708 & 0.4915 & 6 \\
\hline
\end{tabular}

changed from 11 to 12 amps. A decrease in surface roughness by $3.54 \%$ and an increase in surface roughness by $10.36 \%$ and $4.92 \%$ are seen during the curvature and inclined cutting, when input current is changed from 12 to $13 \mathrm{amp}$.

In the analysis of experimental data for the surface roughness response using the Taguchi method in MINITAB 18 , smaller is the better approach of normalization is used. The step-wise calculation for the GRA is shown in Tables 5 and 6 , respectively.

From the GFRG, the optimized response parameters are surface roughness for the straight cut is 2.549 microns, for curvature cut is 2.469 , and for the inclined cut is 2.605 microns. The optimized values are related to trial 1 and subjected to the input parameters pulse on time 108 microsec, pulse off time 56 microsec, wire feed rate $4 \mathrm{~m} / \mathrm{min}$, and the current $11 \mathrm{amp}$.

The fuzzy logic technique is applied to identify the suspicions in the various parameters which are not clear. The fuzzy reasoning grade using the fuzzy logic approach can be used to reduce the uncertainties. The fuzzy-based technique of grey-fuzzy relational grade (GFRG) produces the results with lesser uncertainties than the normal approach. The GFRG is performed in the FIS editor in Matlab. Three fuzzy subsets are consigned for each response grey relational grade as shown in Figure 7, triangular membership function (mamdani) with three levels as low, medium, and high as shown in Figure 8 and 9. In the fuzzy logic, if-then rule statements are applied to the three grey relational coefficients such as surface roughness during the straight, curvature, and inclined machining with one response as the 


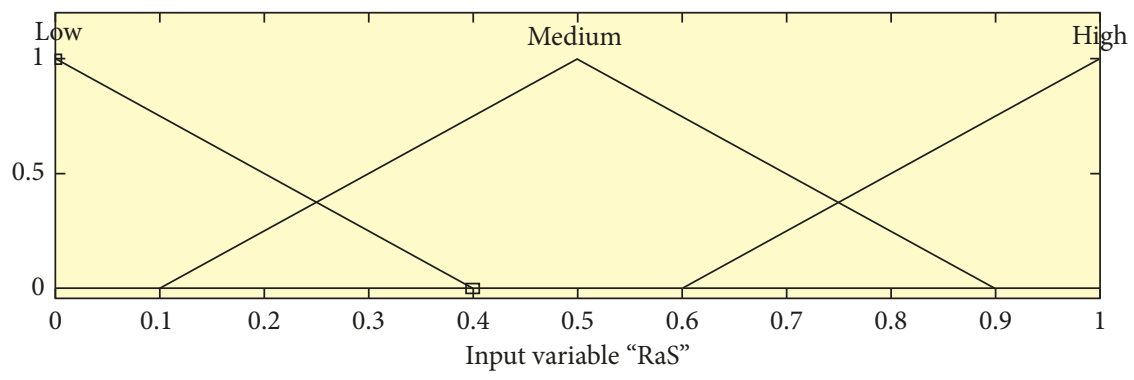

FIgURE 8: Triangular membership function used in the FIS.

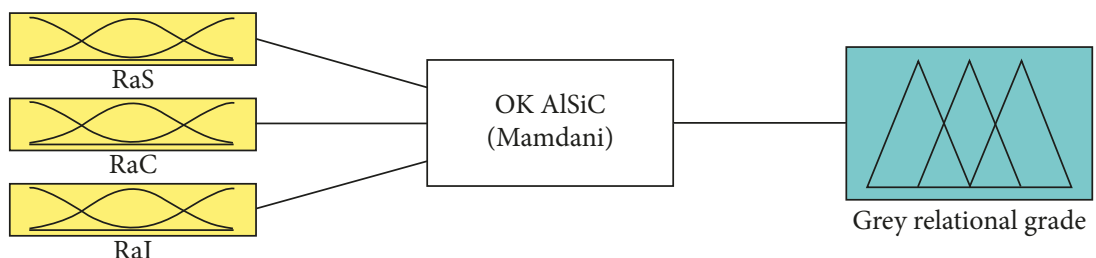

FIgURE 9: Fuzzy editor in the FIS.

TABLe 7: Fuzzy subsets used for the GFRG.

\begin{tabular}{lccc}
\hline Sr. no. & Range & Level & Membership function \\
\hline 1 & {$\left[\begin{array}{lll}-0.5 & 0 & 0.5\end{array}\right]$} & Low $(\mathrm{L})$ & Triangular membership function \\
2 & {$\left[\begin{array}{llll}0.5 & 0.5 & 1.0\end{array}\right]$} & Medium $(\mathrm{M})$ & High $(\mathrm{H})$ \\
3 & {$\left[\begin{array}{lll}0.5 & 1.0 & 1.5\end{array}\right]$} & \\
\hline
\end{tabular}

$\mathrm{RaS}=1$

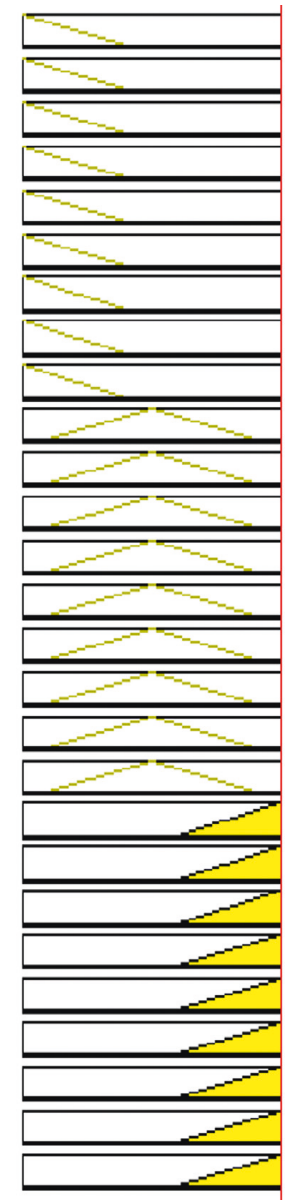

$\mathrm{RaC}=0.885$

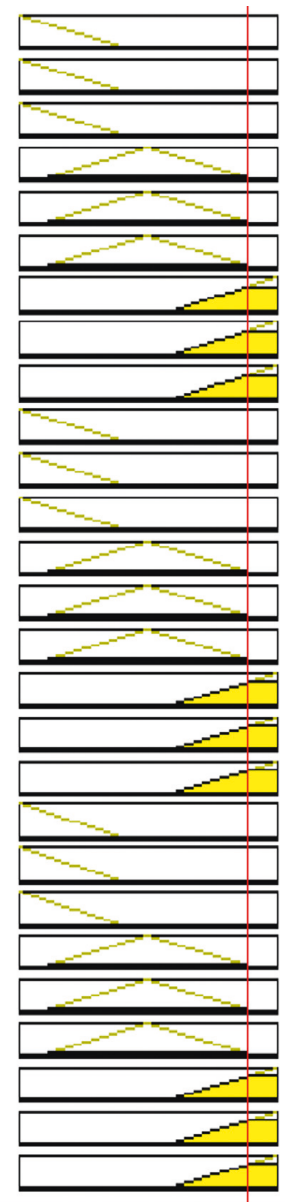

$\mathrm{RaI}=0.749$

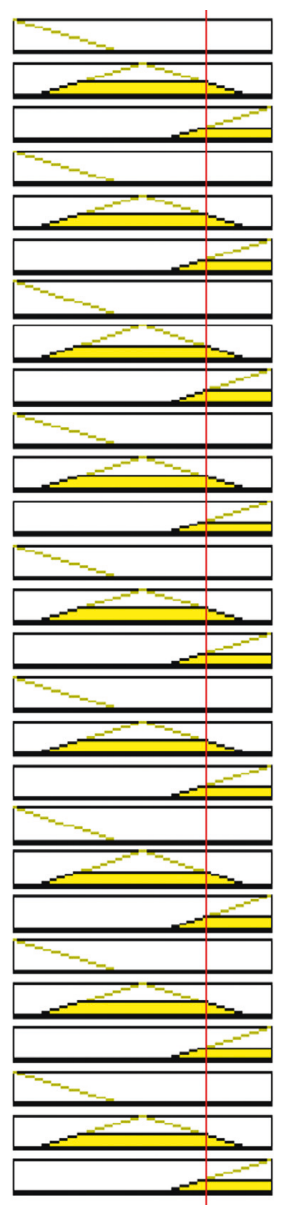

Grey relational grade $=0.899$

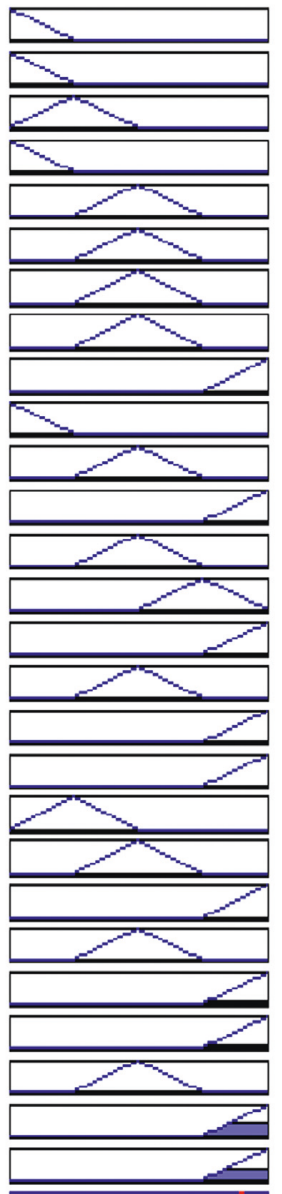

(a)

Figure 10: Continued. 


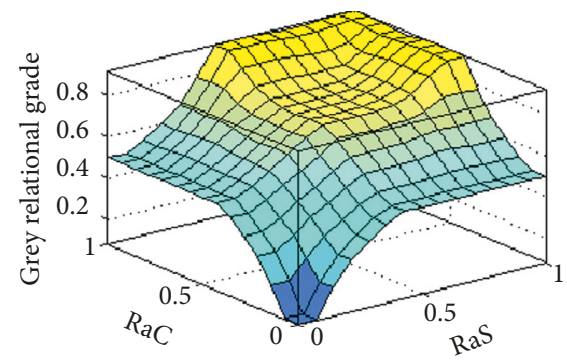

(b)

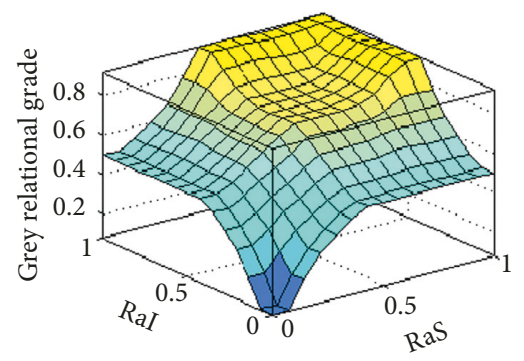

(c)

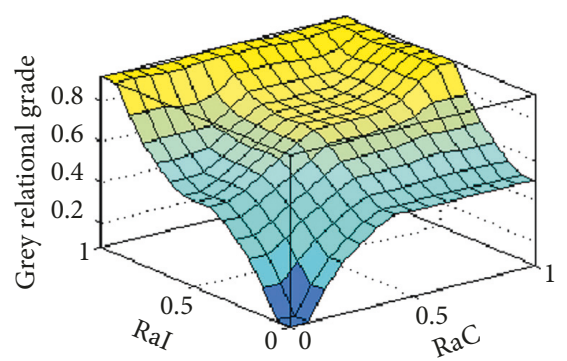

(d)

FIgURE 10: Influence of output responses on GFRG.

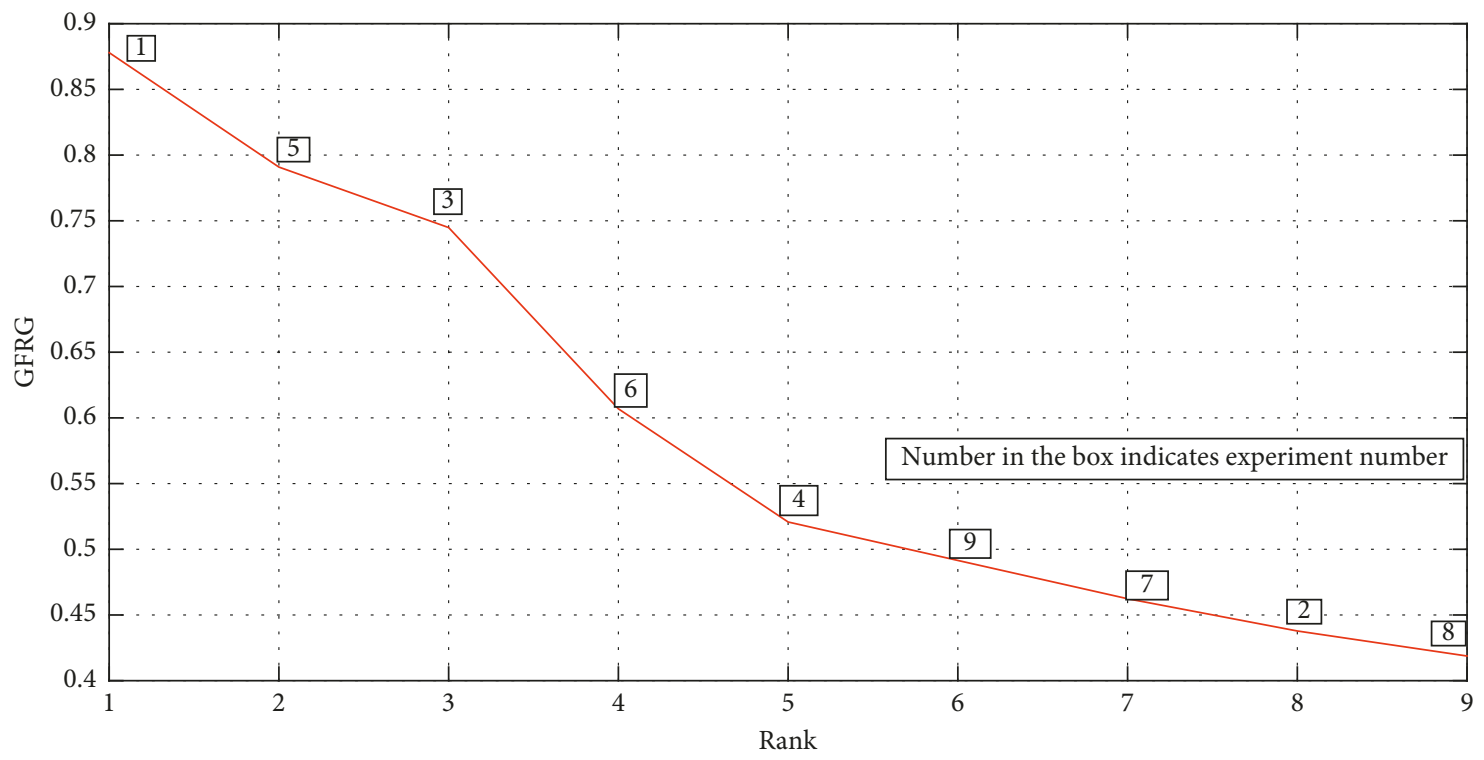

FIGURE 11: GFRG for the responses.

grey-fuzzy reasoning grade. The fuzzy subsets that are used in the present work are shown in Table 7.

For activating the fuzzy inference system (FIS), a set of rules are used which is as shown in Figure 10 and discussed in Section 3.5. The GFRG are shown in the surface plot shown in Figure 10.

Table 7 shows the GFRG from the fuzzy logic tool box. The results of grey relational grade (GRG) and grey-fuzzy reasoning grade (GFRG) are correlated. From the result, it has been seen that there is significant enhancement in the GFRG values which reduces the uncertainty and fuzziness. From the ranking, it is confirmed that experiment no. 1 has the uppermost value of GFRG. It indicates that experiment no 1 has the optimized set of process parameters (Figure 11).

From the GFRG Table 8, the optimum level of parameters are selected as pulse on time of 108 microsec, pulse off time as 56 microsec, wire feed rate as $4 \mathrm{~m} / \mathrm{min}$, and the current as $11 \mathrm{amp}$ represented by 1-1-1-1 level. The main effect plot of GFRG is plotted from the experimental responses, as shown in Figure 12. The GFRG responses are shown in Table 9. The if-then rule set and the influence are shown in Figure 10. The comparison between grey relational grade and the grey-fuzzy reasoning grade is as shown in Figure 13.

From the main effect plot, it has been observed that the there is a steep slope of parameters pulse on, wire feed rate, and the current. Hence, these parameters showed the most influence than the parameter pulse off time. The interaction plot between parameters of various processes considered for the investigation over the grey-fuzzy reasoning grade is shown in Figure 14. The interaction plot shows the relationship between the response variables and the categorical factorial or the input parameters. The interaction plot displays the means for levels of one factor on the horizontal axis and a separate line for other factors. The lines represent the interaction effect between the response variable and the factor. The parallel lines show no interaction, while the nonparallel lines show the interaction effect. The more the nonparallel lines, the greater the interaction.

From Figure 14, it has been observed that the lines are not parallel. This indicates that the relationship between pulse on time and the response GFRG depends on the other 
TABLE 8: Calculation of the grey-fuzzy reasoning grade (GFRG) for the responses.

\begin{tabular}{lccc}
\hline Trial no & Grey relational grade & Grey-fuzzy reasoning grade & \% enhancement \\
\hline 1 & 0.878 & 0.899 & 2.3918 \\
2 & 0.438 & 0.69 & 57.534 \\
3 & 0.745 & 0.91 & 22.148 \\
4 & 0.521 & 0.75 & 43.954 \\
5 & 0.791 & 0.907 & 14.665 \\
6 & 0.607 & 0.756 & 24.547 \\
7 & 0.463 & 0.688 & 48.596 \\
8 & 0.419 & 0.683 & 63.007 \\
9 & 0.492 & 0.495 & 0.6098 \\
\hline
\end{tabular}

TABLE 9: GFRG response table.

\begin{tabular}{lcccc}
\hline Level/parameters & $T_{\text {ON }}$ & $T_{\text {OFF }}$ & WFR & IP \\
\hline Level 1 (first) & 0.8330 & 0.7790 & 0.7793 & 0.7670 \\
Level 2 (second) & 0.8043 & 0.7600 & 0.6450 & 0.7113 \\
Level 3 (third) & 0.6220 & 0.7203 & 0.8350 & 0.7810 \\
Delta & 0.2110 & 0.0587 & 0.1900 & 0.0694 \\
Influencing order & 1 & 4 & 2 & 3 \\
\hline
\end{tabular}

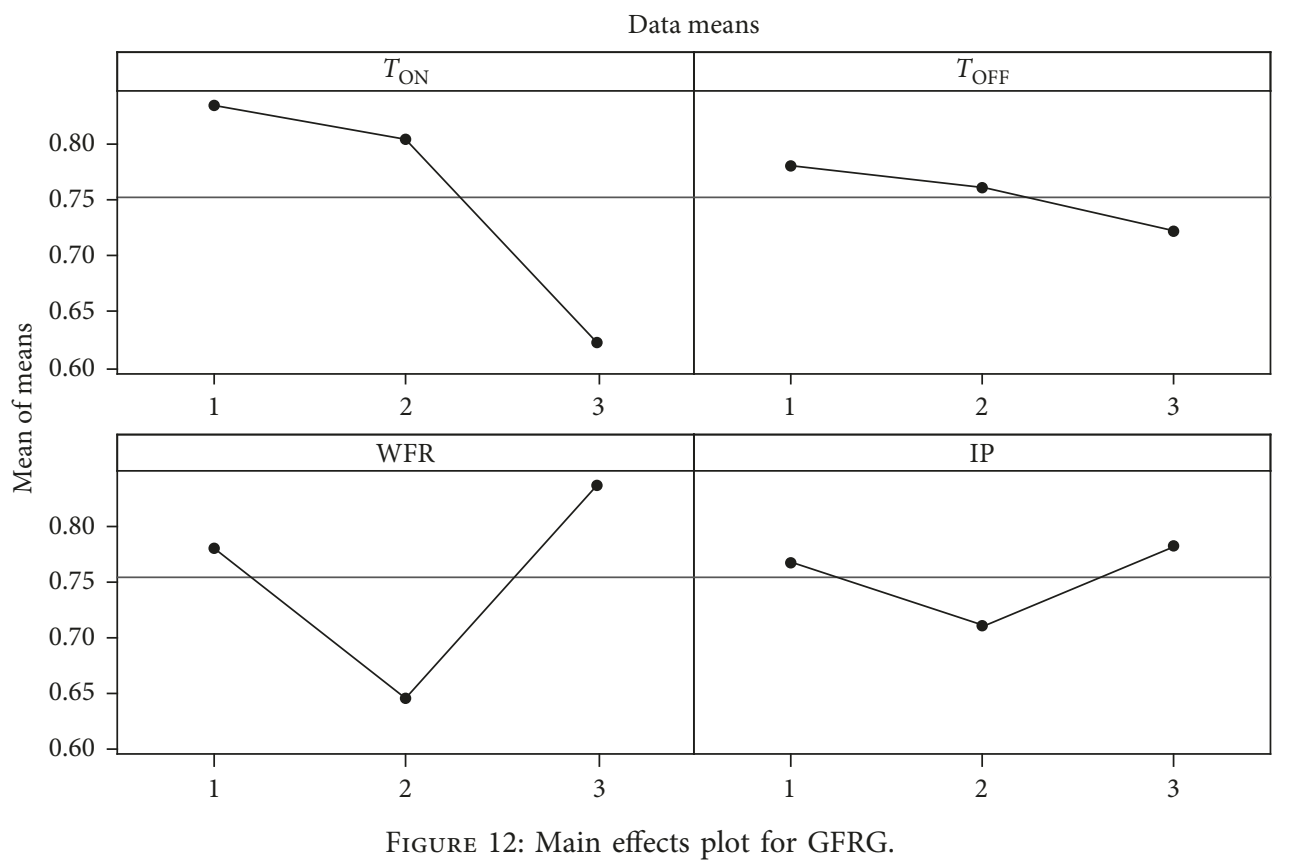

factors, pulse off time, wire feed rate, and the input current, and vice versa. The microscopic structure of $\mathrm{Al} / \mathrm{SiC} \mathrm{MMC} \mathrm{is}$ shown in Figure 15.

The ANOVA is carried out for the obtained GFRG which shows the impact of various process parameters from $\mathrm{Ta}-$ ble 10; it had been observed that the obtained ANOVA table does not give sufficient results since the degrees of freedom (DOF) for the error term is zero. This happens due to the mismatching of the input parameters and the level of each parameter. For this situation, pooling is preferred. In pooling, the factor which shows the least effect on the response parameter is neglecting from the analysis. The ANOVA results after the pooling are shown in Table 11. In this analysis, pulse off time is having least effect on the response, hence neglected.

From ANOVA Table 11 (after Pooling), it is seen that the pulse on time $\left(T_{\mathrm{ON}}\right)$ is the major influencing parameter that contributes towards GFRG by $52.61 \%$, followed by the wire feed rate (WFR) $38.32 \%$, and the current by $5.45 \%$. The " $S$ " value of ANOVA is 0.0518470 , and $R^{2}$ is $96.40 \%$ which shows the good acceptable results.

\section{Conclusions}

The conclusion obtained from the presented approach is as follows. 


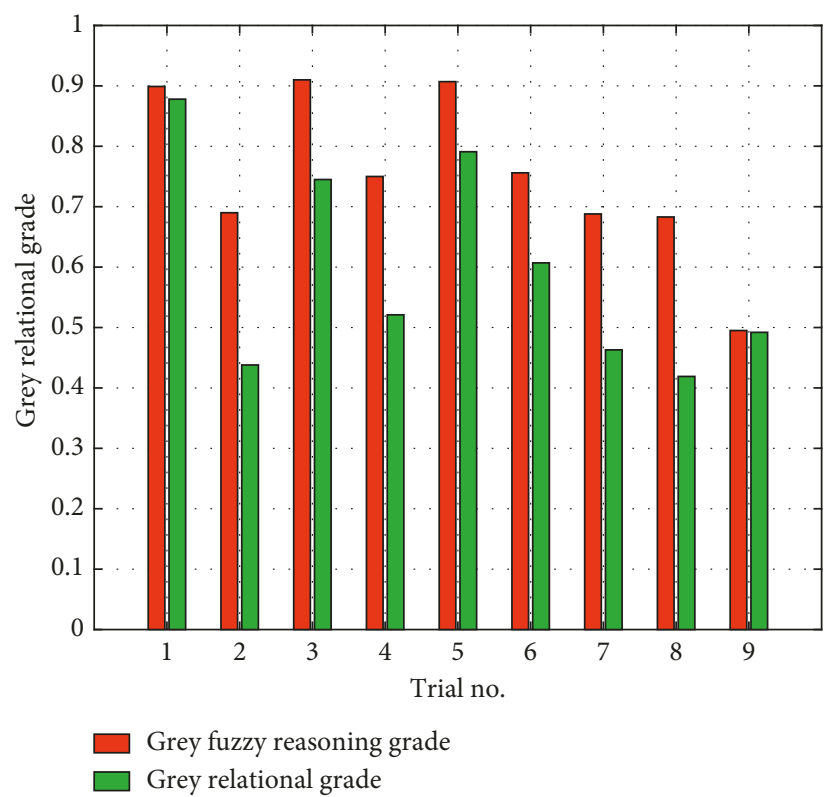

Figure 13: Comparison between obtained GRG and GFRG.

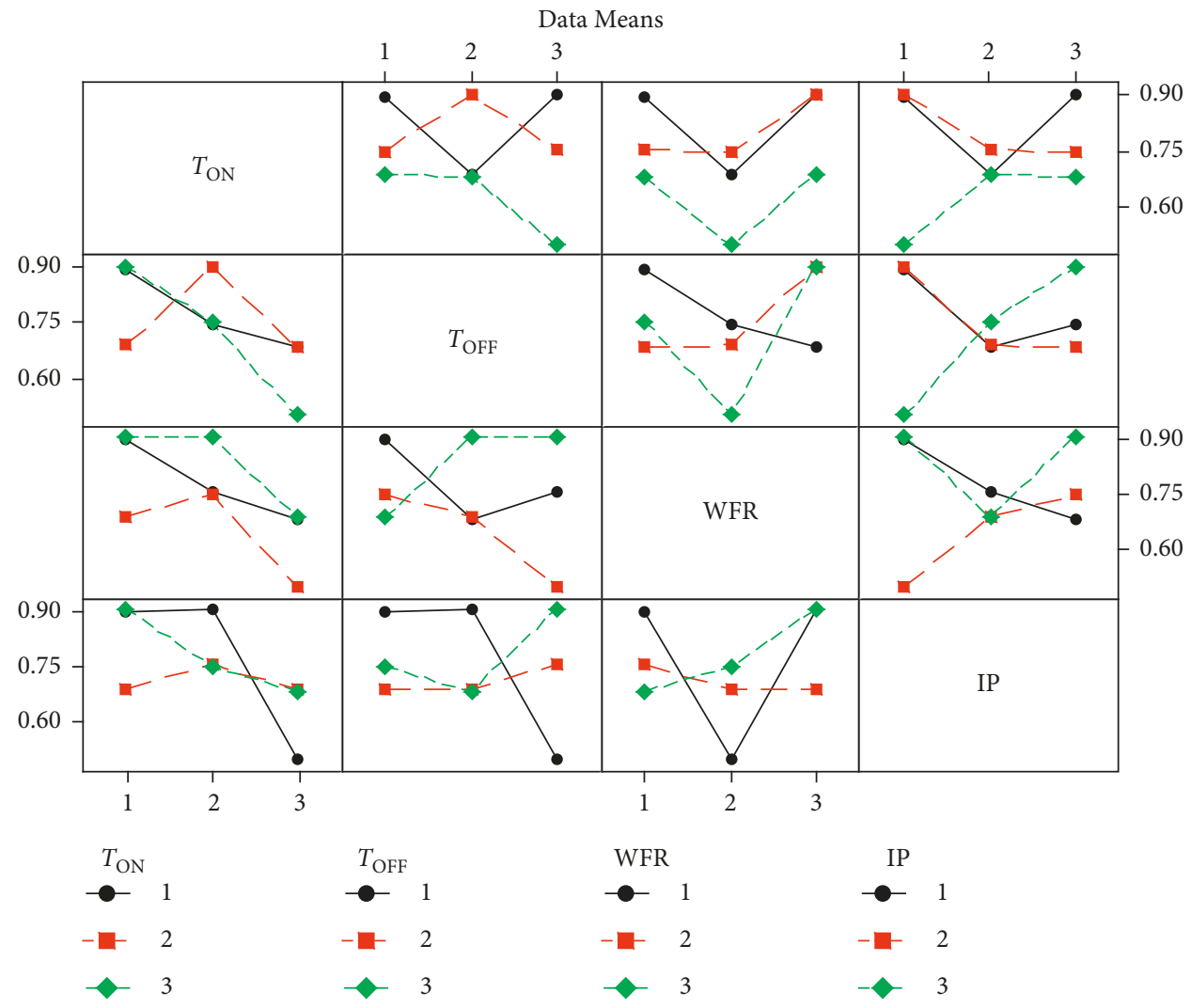

Figure 14: Interaction plot for GFRG.

(i) The experiments are conducted using Taguchi's $\mathrm{L}_{9}$ arrays. The analysis is done by fuzzy-grey relational analysis for multiresponse optimization.

(ii) The optimum level of the input parameters obtained are pulse on time 108 microsec, pulse off time 56 microsec, wire feed rate $4 \mathrm{~m} / \mathrm{min}$, and current $11 \mathrm{amp}$. (iii) The interaction plots show that there is an interaction effect of the process parameters.

(iv) From the ANOVA table (after pooling), it is observed that the pulse on time $\left(T_{\mathrm{ON}}\right)$ is the most influencing parameter that contributes towards GFRG by $52.61 \%$, followed by the wire feed rate 


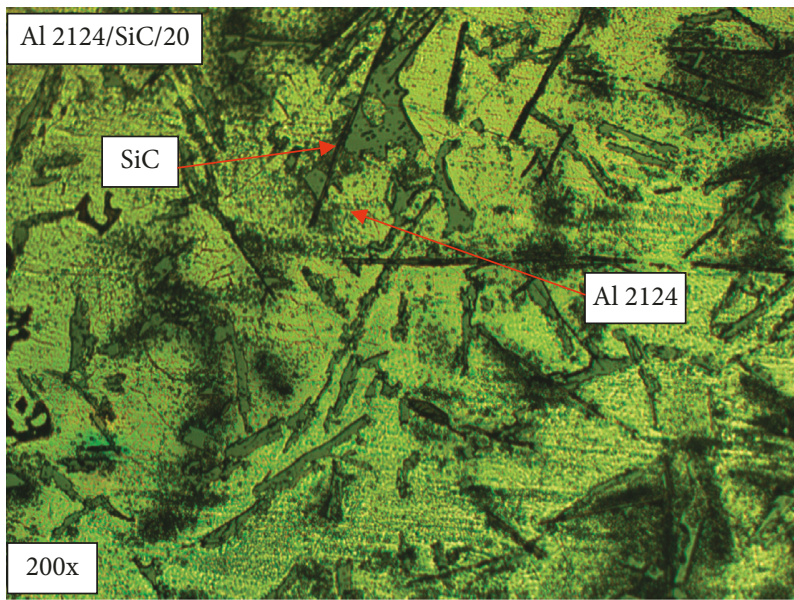

FIGURE 15: Microstructure at 200x (after itching) shows eutectic Si and SiC particle in the matrix of $\alpha$-aluminium (for AlSiC20\%).

TABLE 10: ANOVA table for GFRG (before pooling).

\begin{tabular}{|c|c|c|c|c|c|c|}
\hline Source & Degree of freedom & $\mathrm{SS}^{2}$ & Adj. MS & $\mathrm{F}$ & $P$ & $\%$ contribution \\
\hline$\overline{T_{\mathrm{ON}}}$ & 2 & 0.078588 & 0.039294 & * & $*$ & * \\
\hline$T_{\mathrm{OFF}}$ & 2 & 0.005376 & 0.002688 & * & $*$ & $*$ \\
\hline WFR & 2 & 0.057244 & 0.28622 & $*$ & $*$ & $*$ \\
\hline IP & 2 & 0.008148 & 0.004074 & * & $*$ & $*$ \\
\hline Error & 0 & $*$ & $*$ & & & $*$ \\
\hline Total & 8 & 0.149357 & & & & \\
\hline
\end{tabular}

TABLE 11: ANOVA table for GFRG (after pooling).

\begin{tabular}{|c|c|c|c|c|c|c|}
\hline Source & Degree of freedom & $\mathrm{SS}^{2}$ & Adj. MS & $F$ & $P$ & $\%$ contribution \\
\hline$\overline{T_{\mathrm{ON}}}$ & 2 & 0.078588 & 0.039294 & 14.62 & 0.064 & 52.61755 \\
\hline WFR & 2 & 0.057244 & 0.28622 & 10.65 & 0.086 & 38.32696 \\
\hline IP & 2 & 0.008148 & 0.004074 & 1.52 & 0.398 & 5.45538 \\
\hline Error & 0 & 0.005376 & 0.002688 & & & 3.59943 \\
\hline Total & 8 & 0.149357 & & & & 100 \\
\hline$S=0.0518470$ & & \multicolumn{2}{|c|}{$R^{2}=96.40 \%$} & \multicolumn{3}{|c|}{$R^{2}(\mathrm{adj})=85.60 \%$} \\
\hline
\end{tabular}

(WFR) by $38.32 \%$, and the current by $5.45 \%$. The " $S$ " value of ANOVA is 0.0518470 , and $R^{2}$ is $96.40 \%$.

(v) From the literature review, it has been observed that the GFRG is the easy and effective tool which helps us to analyze the multiresponse process in a very effective and efficient way as compare to the other tools.

\section{Data Availability}

The data used to support the findings of this study are available from the corresponding author upon request.

\section{Conflicts of Interest}

The authors declare that there are no conflicts of interest regarding the publication of this paper.

\section{Acknowledgments}

The authors would like to acknowledge and thank Kakade Laser Pvt. Limited Pune, Maharashtra, India, for supporting the present work.

\section{References}

[1] M. R. Phate and V. H. Tatwawadi, "Mathematical model of material removal rate and power consumption for dry turning of ferrous material using dimensional analysis in Indian prospective," Jordon Journal of Mechanical and Industrial Engineering, vol. 9, no. 1, pp. 351-362, 2015.

[2] M. R. Phate, V. H. Tatwawadi, and J. P. Modak, "Formulation of a Generalized field data based model for the surface roughness of aluminum 6063 in dry turning operation," New York Science Journal, vol. 5, no. 7, pp. 38-46, 2012.

[3] A. Ilhan and C. Mehmet, "Modeling and prediction of surface roughness in turning operation using artificial neural network 
and multiple regression method," Expert System with Applications, vol. 38 , no. 5, pp. 5826-5832, 2011.

[4] V. N. Gaitonde, S. R. Karnik, L. Figueira, and J. P. Davim, "Performance comparison of conventional and wiper ceramic inserts in hard turning through artificial neural network modeling," International Journal of Advanced Manufacturing Technology, vol. 52, no. 1-4, pp. 101-114, 2010.

[5] I. M. Jamadar and D. O. Vakharia, "A novel approach integrating dimensional analysis and neural network for the detection of localized faults in roller bearings," Measurement, vol. 94, no. 1, pp. 177-185, 2010.

[6] R. Bobbili, V. Madhu, and A. K. Gogia, "Modelling and analysis of material removal rate and surface roughness in wire-cut EDM of armour materials," Engineering Science and Technology, An International Journal, vol. 18, no. 4, pp. 664-668, 2015.

[7] M. Kolli and A. Kumar, "Effect of dielectric fluid with surfactant and graphite powder on electrical discharge machining of titanium alloy using Taguchi method," Engineering Science and Technology, An International Journal, vol. 18, no. 4, pp. 524-535, 2015.

[8] A. Saha and S. C. Mondal, "Multi-objective optimization in WEDM process of nanostructured hardfacing materials through hybrid techniques," Measurement, vol. 94, pp. 46-59, 2016.

[9] J. R. Mevada, “A comparative experimental investigation on process parameters using molybdenum, brass and zinc-coated wires in wire cut EDM," International Journal of Scientific \& Engineering Research, vol. 4, no. 7, pp. 1398-1407, 2015.

[10] Y. Huang, W. Ming, J. Guo et al., "Optimization of cutting conditions of YG15 on rough and finish cutting in WEDM based on statistical analyses," International Journal of Advanced Manufacturing Technology, vol. 69, no. 5-8, pp. 9931008, 2013.

[11] C.-J. Tzeng, Y.-K. Yang, M.-H. Hsieh, and M.-C. Jeng, "Optimization of wire electrical discharge machining of pure tungsten using neural network and response surface methodology," Proceedings of the Institution of Mechanical Engineers, Part B: Journal of Engineering Manufacture, vol. 225, no. 6, pp. 841-852, 2011.

[12] M. R. Phate and V. H. Tatwawadi, Field Data Based Model (FDBM): A Heuristic Approach Research, Lambert Academic Publication, Saarbrücken, Germany, 2014.

[13] M. R. Phate, C. K. Mahajan, M. L. Mote, B. V. Patil, and H. G. Patil, "Investigation of turning process using field data based approach in Indian small scale industries," International Journal of Research in Mechanical Engineering and Technology (IJRMET), vol. 3, no. 2, pp. 7-13, 2013.

[14] M. R. Phate and S. B. Toney, "Formulation of artificial neural network (ANN) based model for the dry machining of ferrous \& non-ferrous material used in Indian small scale industries," International Journal of Materials Science and Engineering, vol. 4, no. 3, pp. 145-160, 2016.

[15] R. S. Kadu, G. K. Awari, C. N. Sakhale, and J. P. Modak, "Formulation of mathematical model for the investigation of tool wears in boring machining operation on cast iron using carbide and CBN tools," Procedia Materials Science, vol. 6, pp. 1710-1724, 2014.

[16] P. S. Rao, K. Ramji, and B. Satyanarayana, "Effect of wire EDM conditions on generation of residual stresses in machining of aluminum 2014 T6 alloy," Alexandria Engineering Journal, vol. 55, no. 2, pp. 1077-1084, 2016.

[17] H. Schenck Jr., Theories of Engineering A Experimentation, McGraw Hill Book Co, New York, NY, USA, 1954.
[18] M. Gupta and S. Kumar, "Investigation of surface roughness and MRR for turning of UD-GFRP using PCA and Taguchi method," Engineering Science and Technology, an International Journal, vol. 18, no. 1, pp. 70-81, 2015.

[19] S. Kumar and U. Batra, "Surface modification of die steel materials by EDM method using tungsten powder-mixed dielectric," Journal of Manufacturing Processes, vol. 14, no. 1, pp. 35-40, 2012. 


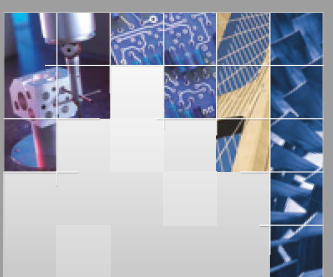

\section{Enfincering}
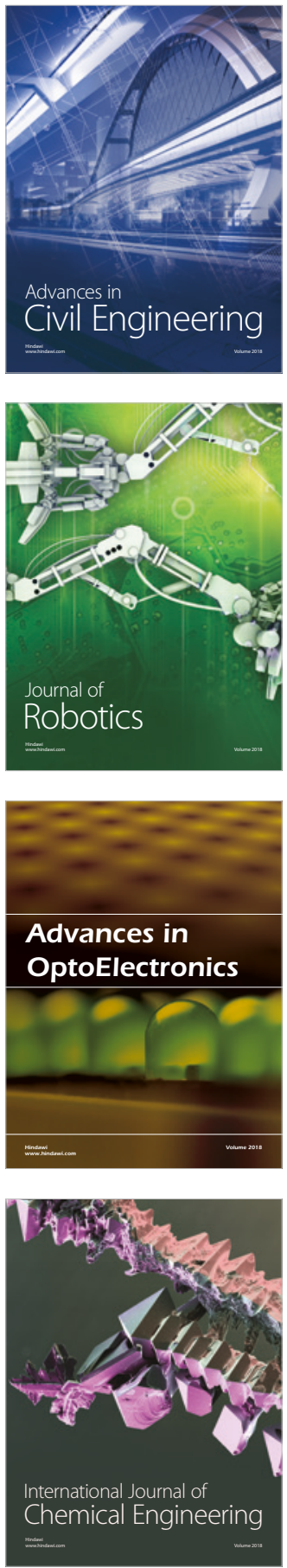

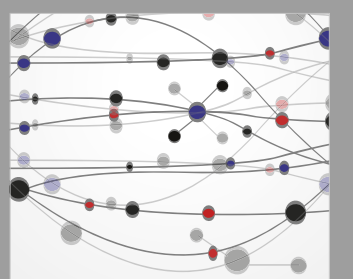

\section{Rotating \\ Machinery}

The Scientific World Journal

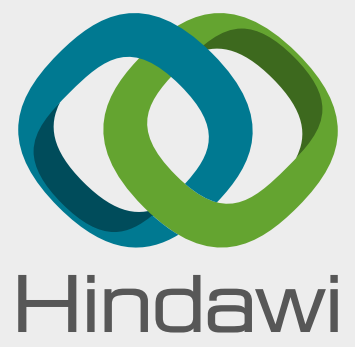

Submit your manuscripts at

www.hindawi.com
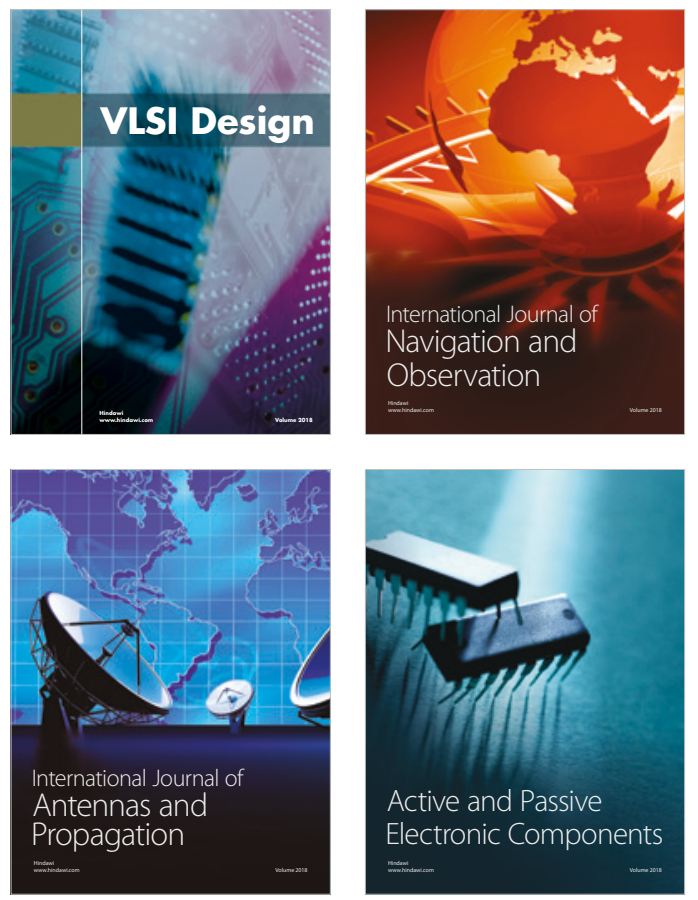
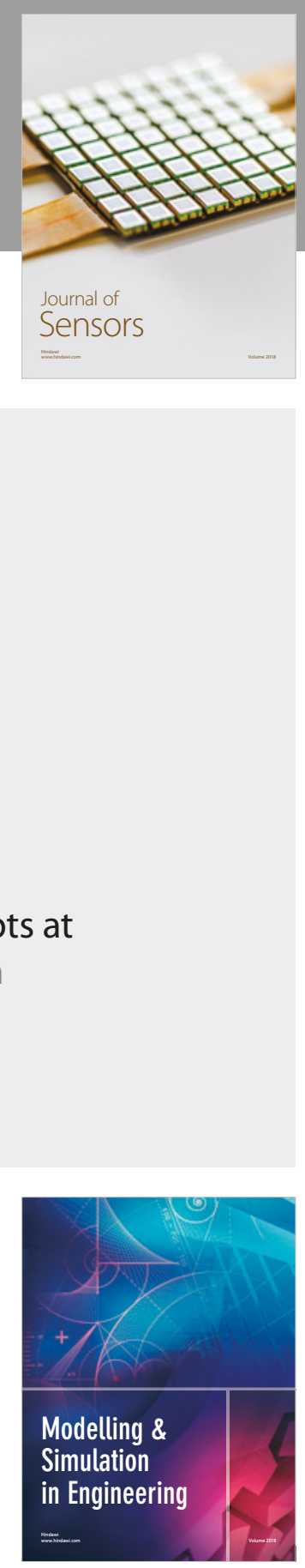

\section{Advances \\ Multimedia}
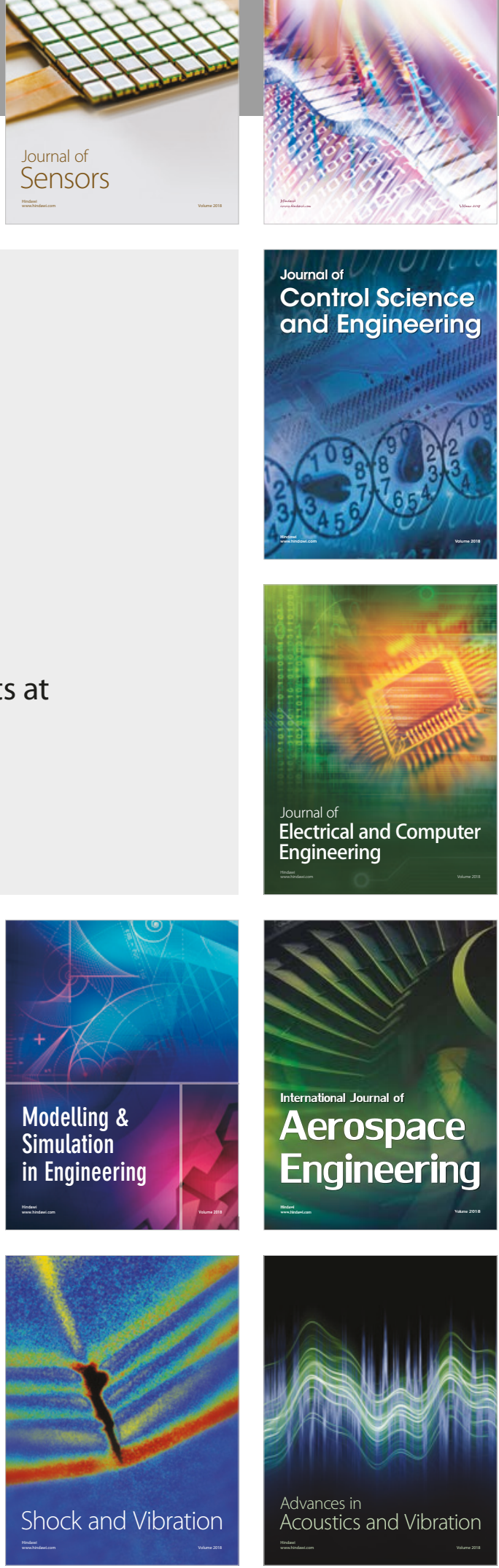